\title{
EFFECTS OF THE 2014 FARM BILL POLICIES ON COTTON PRODUCTION
}

\author{
STEPHEN DEVADOSS* \\ Department of Agricultural and Applied Economics, Texas Tech University, Lubbock, Texas \\ JEFF LUCKSTEAD \\ Department of Agricultural Economics and Agribusiness, University of Arkansas, Fayetteville, Arkansas
}

\begin{abstract}
We develop a model for a representative risk-averse cotton farmer to analyze the impact of crop insurance policies (Revenue Protection [RP], Yield Protection, Stacked Income Protection Plan [STAX], and Supplemental Coverage Option [SCO]). The model is calibrated and numerically optimized to quantify the effects of different insurance policy combinations on input use (moral hazard), insurance coverage levels, premiums, and certainty equivalent. When the farmer elects only RP, the optimal coverage rate is $80 \%$. Under RP and STAX, the optimal RP coverage rate is $70 \%$ and the STAX coverage rate is $90 \%$. RP and STAX is the optimal policy combination based on certainty equivalents. The RP and SCO combination has the lowest impact of input use.
\end{abstract}

Keywords. Cotton, crop insurance, moral hazard, RP, SCO, STAX, YP

JEL Classification. Q18

\section{Introduction}

The Agricultural Act of 2014 has made risk management through crop insurance a cornerstone of government support for cotton producers. For cotton, this Farm Bill eliminated commodity programs and focused on risk management because of the U.S.-Brazil cotton dispute where the World Trade Organization (WTO) found the U.S. government to be unfairly subsidizing cotton producers (Campiche, 2014; Luitel et al., 2015a). Because Title I commodity programs do not cover upland cotton, cotton base acres are no longer available for cotton for the new 2014 commodity programs such as Agriculture Risk Coverage and Price Loss Coverage. ${ }^{1}$ Consequently, since 2014 cotton producers may rely more on crop insurance than producers of other crops because cotton was moved from a Title I commodity to a Title II Stacked Income Protection Plan (STAX).

\footnotetext{
*Corresponding author’s e-mail: stephen.devadoss@ttu.edu
}

The project was supported by the Economic Research Service of the U.S. Department of Agriculture under the Cooperative Agreement, Project Number 58-3000-4-0029.

1 However, other crops can be grown on these base acres under Title I commodity programs. 
Cotton policies under the 2014 Farm Bill include marketing assistance loan/loan deficiency payments ${ }^{2}$ and cotton crop insurance policies. Under the 2014 Farm Bill, cotton farmers have the option of participating in previously established Revenue Protection (RP) or Yield Protection (YP) insurance programs and the new STAX or Supplemental Coverage Option (SCO). ${ }^{3}$ The RP and YP policies are deep-loss coverage programs because they cover revenue (RP) or yield (YP) losses based on the chosen coverage level and the remaining uncovered losses (i.e., the deductibles) are absorbed by the farmer. However, STAX and SCO are shallow-loss programs because these are supplemental programs to RP or YP and can cover part of the deductible of the deep-loss programs. STAX can be an independent policy or bought with RP or YP. In contrast, a cotton farmer must be enrolled in a deep-loss coverage program to be eligible for SCO. STAX is a revenue protection program, whereas SCO is either a revenue or yield protection program depending whether SCO is in conjunction with the RP or YP policy. Although the loss costs (or payment rates) under STAX and SCO are similar in structure and cover county-wide losses, the liability is based on county yield under STAX but on farm-level actual production history (APH) yield under SCO. Thus, indemnity payments (loss cost times liability) differ between the two policies. Furthermore, STAX was introduced in the 2014 Farm Bill to provide minimal policy support to cotton producers in the wake of the WTO ruling on the U.S.-Brazil cotton dispute. Thus, the crop insurance policy options for farmers are (a) RP, (b) YP, (c) STAX, (d) RP with STAX or SCO, or (e) YP with STAX or SCO.

Several studies have examined the effects of cotton policies that were proposed before the Farm Bill was legislated. Outlaw et al. (2012), Karov, Wailes, and Watkins (2012), and Campiche (2013a, 2013b) analyzed the cotton policies that were debated before the introduction of the Farm Bill. Outlaw et al. (2012) studied the effects of the Senate and House versions of the STAX program on representative farms and found that the House bill, with the inclusion of a minimum reference price, provided larger protection than the Senate bill. Karov, Wailes, and Watkins (2012) found that average payments under STAX ranged from $\$ 1$ to $\$ 46$ per acre for the coverage levels of $70 \%$ to $95 \%$. Furthermore, their results showed that almost all cotton farms would not benefit as much from STAX as opposed to the direct payments covered under the 2008 Farm

2 The marketing assistance loan program allows producers to receive a loan from the U.S. government using their output as collateral. The loan deficiency payment policy works similar to a marketing assistance loan, but a farmer never uses the commodity as collateral. Farmers can enroll either in the marketing assistance loan or loan deficiency payment program, but not both (U.S. Department of Agriculture, Farm Service Agency, 2014). We do not model these policies because the loan rate (49.49 cents per pound) is too low to trigger payments.

3 Cotton farmers can also participate in RP-HPE (RP with the harvest price exclusion). However, according to the U.S. Department of Agriculture, Risk Management Agency (2017), cotton farmers rarely elect RP-HPE. Thus, this policy is not considered for the analysis. 
Bill. Similar to the findings of Karov, Wailes, and Watkins (2012), Campiche (2013a) observed that cotton producers in Oklahoma and Texas generally benefited more from Counter-Cyclical Payment/Direct Payment programs than under STAX or SCO policies. Furthermore, Campiche noted that direct payments were fixed payments, but STAX and SCO payments fluctuated year to year, and farmers may not have received any payments depending on the market prices and yield. In addition, Campiche's analysis showed that farmers generally received larger payments under STAX than SCO. Campiche (2013b) compared Counter-Cyclical Payment/Direct Payment programs with STAX under the House bill for a representative farm with 900 planted acres (or 1,200 base acres) and concluded that payments under Counter-Cyclical Payment/Direct Payment programs $(\$ 72,828)$ were higher than under STAX $(\$ 42,861)$.

Some studies have also examined the impacts of the cotton policies that were passed under the 2014 Farm Bill. Davis, Anderson, and Smith (2014) found that the STAX program with the $120 \%$ multiplier results in an annualized net payment of $\$ 163$ per acre for an average Texas irrigated cotton farm. Their results showed, when RP and STAX are both selected, indemnity payments from both programs range from $\$ 163.46$ to $\$ 35.25$ for RP coverage rates from $55 \%$ to $85 \%$, respectively. Thus, farmers preferred lower RP coverage, which reduces insurance premiums because they benefit from larger STAX payments. Bulut and Collins (2014) also observed that a combination of crop insurance and supplemental revenue insurance policies provide larger benefits to farmers. Furthermore, they found that, similar to the results of Davis, Anderson, and Smith (2014), supplemental revenue programs generally lower the coverage level of crop insurance policies. Luitel et al. $(2015 \mathrm{~b})$, in assessing the benefits of crop insurance payments for cotton producers in the Texas High Plains, found that revenue protection at the $70 \%$ coverage level along with STAX at $90 \%$ coverage is the optimal policy combination based on certainty equivalents. Adhikari (2015) examined different coverage levels for RP, YP, RP and SCO, and YP and SCO crop insurance programs for cotton. The results showed that the optimal coverage level varies across counties, and individual crop insurance policies with SCO result in better protection.

We focus our analysis on the interaction of existing deep-loss (RP and YP) and new 2014 shallow-loss (STAX and SCO) crop insurance programs. ${ }^{4}$ As in any insurance policy, these crop insurance policies can involve moral hazard as farmers can alter their production decisions to secure larger indemnity payments because of asymmetric information. STAX and SCO control for these insurance pitfalls by decoupling indemnity payments from production decisions.

\footnotetext{
4 Because direct payments or the cotton transition assistance program are no longer available, and marketing assistance loan and loan deficiency payments accrue only in very rare cases because the loan rate $(49.49$ cents per pound) is well below the market price for upland cotton (average of 61.30 cents per pound for 2015-2016), we do not consider these policies in the analysis.
} 
However, because farm-level outcomes are not perfectly correlated with countylevel outcomes, STAX and SCO suffer from basis risk. ${ }^{5,6}$ The objectives of this article are to (a) develop a model to analyze the impact of crop insurance policies (RP, YP, STAX, and SCO) for a representative risk-averse cotton farmer; (b) estimate the trivariate distribution for cotton county yield, farm-level yield, and price; (c) calibrate the model to a representative cotton farm; (d) numerically optimize the model to simulate the effects of these crop insurance policies on production decisions, insurance coverage levels, and insurance payments; and (e) determine optimal combination of insurance polices for the representative cotton farmer.

Previous literature has studied the benefits from past commodity programs and the current cotton insurance policies (RP, YP, STAX, and SCO) to cotton farmers. However, this literature does not optimally determine input use, resulting in payments based on a given yield. The contribution of our study to the literature is to build a model that allows cotton farmers to optimally choose both input use and insurance coverage levels. The simulation results for the certainty equivalent also determine the optimal combination of deep- and shallow-loss policies, while endogenously determining yield.

\section{Model}

We develop a model of a risk-averse cotton farmer who faces random cotton price and yield. This farmer has three potential sources of income: market revenues from selling cotton, deep-loss crop insurance from RP or YP, and shallow-loss crop insurance from STAX or SCO. The farmer maximizes utility from income by simultaneously choosing input levels and insurance coverage levels. Because of the planting date requirement ${ }^{7}$ to participate in crop insurance, inputs used in planting operations are not considered as variable inputs for the analysis, and the farmer makes only postplanting variable input decisions. Next, we detail each of the three sources of income and then specify the optimization problem.

5 Basis risk occurs because farm-level and county-level outcomes are not perfectly correlated. Thus, although STAX is designed to reduce the farmer's RP deductible, payments are made based on county-level revenue shortfalls, which are less likely to occur than farm-level revenue shortfalls. Therefore, the farmer could have a low revenue, but if the county revenue is average or high, then the farmer will not receive a STAX payment even though he/she could benefit from the support. Conversely, the farmer could have a high revenue, whereas the county revenue is low, and STAX payments are made to the farmer who does not need the support.

6 See Vedenov and Barnett (2004) and Barnett and Mahul (2007) for a detailed discussion. Also note that area insurance products, which mitigate moral hazard and adverse selection but create basis risk, have been part of U.S. agricultural policy for several decades (Skees, Black, and Barnett, 1997).

7 That is, farmers need to plant their crops by a specified date using standard cultivation practices to be eligible for crop insurance. 


\subsection{Market Revenue}

Market revenue $\tilde{r}$ from cotton farming equals stochastic price $\tilde{p}$ times stochastic yield $\tilde{y}: \tilde{r}=\tilde{p} \tilde{y}$, where $\tilde{p}=p+\tilde{\epsilon}^{p}, p$ is the mean price, $\tilde{\epsilon}^{p}$ is the random error term for price that is centered on zero, the production technology is $\tilde{y}=\alpha+\beta x^{\gamma}+\tilde{\epsilon}, \alpha$ is the yield from planting operations alone, $\beta$ is the productivity scale parameter, $x$ is the composite input, ${ }^{8} \gamma$ is the income share parameter for the composite inputs, and $\tilde{\epsilon}$ is the random error term for farm-level yield that is centered on zero. The total cost of production is $t c=w x+f$, where $w x$ is the variable cost, $w$ is the price $\epsilon$ of the composite input, and $f$ is the fixed cost. Profits are market revenues minus total cost:

$$
\pi=\tilde{r}-t c=\tilde{p}\left(\alpha+\beta x^{\gamma}+\tilde{\epsilon}\right)-w x-f .
$$

\subsection{Deep-Loss Crop Insurance Policies}

Deep-loss crop insurance polices include YP and RP. YP crop insurance provides protection only against yield risk. YP indemnity payments $(y p i)$ are

$$
y p i=p^{F} \max \left[0, \eta y^{A}-\tilde{y}\right] \text {. }
$$

where $\eta$ is the coverage level, $y^{A}$ is the APH yield level, and $p^{F}$ is the projected price. ${ }^{9}$ The cotton farmer receives an indemnity payment when actual yield $(\tilde{y})$ falls below the yield guarantee $\left(\eta y^{A}\right)$. Indemnity payments equal the projected price times the difference between the yield guarantee and actual yield. To purchase YP insurance, farmers pay an actuarially fair premium rate $\theta^{Y P}=$ $\int y$ pid $G_{\epsilon^{p}, \epsilon^{C}}(\tilde{\epsilon})$, where $G_{\epsilon^{p}, \epsilon^{C}}(\tilde{\epsilon})$ is the marginal cumulative density for farmlevel yield randomness derived from the joint cumulative density function (CDF) $G\left(\tilde{\epsilon}^{p}, \tilde{\epsilon}, \tilde{\epsilon}^{C}\right)$, which characterizes the price, farm-level yield risk, and county-level yield risk. With government subsidized premiums, net YP indemnity payments $(Y P p)$ are

$$
Y P p=y p i-\left(1-\sigma^{Y P}(\eta)\right) \theta^{Y P},
$$

where government subsidies $\sigma^{Y P}(\eta)$ are inversely related to the coverage level. For YP, coverage levels ${ }^{10}$ are $55 \%, 60 \%, 65 \%, 70 \%, 75 \%, 80 \%$, or $85 \%$,

8 Given the complexity of numerical stochastic optimization (defined in detail in Section 2.4) over inputs and insurance coverage levels, we model only one composite input. Although this is limiting because the literature has shown some inputs can be risk reducing while others are risk enhancing (Roumasset et al., 1989), to the best of our knowledge, our study advances the literature because no simulation-based crop insurance studies have examined the optimal choice of both coverage levels and inputs simultaneously. The implication of modeling only one input is that it can lead to bias in estimating the moral hazard.

9 We assume that the farmer makes crop insurance decisions based on the future price at the time of enrollment.

10 In addition, farmers have the option of enrolling at the catastrophic (CAT) coverage level of $50 \%$ by paying a $\$ 300$ administrative fee. However, for this coverage level, farmers receive payments only at $55 \%$ of the projected price. Because payments are extremely rare at the $50 \%$ coverage level, we do not include CAT coverage in the analysis. 
with corresponding subsidy rates of $64 \%, 64 \%, 59 \%, 59 \%, 55 \%, 48 \%$, or $38 \% .{ }^{11}$ Given these YP coverage levels, the deductible ranges from $45 \%$ to $15 \%$. Expected YP indemnity payments to the farmer are then calculated as

$$
\int Y P p d G_{\epsilon^{p}, \epsilon^{C}}(\tilde{\epsilon})=\sigma^{Y P}(\eta) \theta^{Y P},
$$

because expected indemnity payments are equal to the actuarially fair premium.

$\mathrm{RP}$ crop insurance covers both price and yield risk. RP indemnity payments are

$$
r p i=\max \left[0, \max \left[\tilde{p}, p^{F}\right] \eta y^{A}-\tilde{p} \tilde{y}\right] .
$$

Therefore, the cotton farmer receives indemnity payments when actual market revenues $(\tilde{p} \tilde{y})$ fall below the revenue guarantee $\left(\max \left[\tilde{p}, p^{F}\right] \eta y^{A}\right)$. The indemnity payments equal the difference between the guarantee and market revenues. Farmers pay an actuarially fair premium $\left(\theta^{R P}\right)$ to buy the RP crop insurance: $\theta^{R P}=\iint r p i d G_{\varepsilon^{c}}\left(\tilde{\epsilon}^{p}, \tilde{\varepsilon}\right)$, where $G_{\varepsilon^{c}}$ is the marginal cumulative density. The government subsidizes the premium based on the coverage level. Then, net RP indemnity payments $(R P p)$ to farmers are

$$
R P p=r p i-\left(1-\sigma^{R P}(\eta)\right) \theta^{R P},
$$

where government subsidy rates $\sigma^{R P}(\eta)$ are also inversely related to the coverage level. Under the 2014 Farm Bill, farmers can select a coverage levels of $50 \%$, $55 \%, 60 \%, 65 \%, 70 \%, 75 \%, 80 \%$, or $85 \%$, with corresponding subsidy rates of $67 \%, 64 \%, 64 \%, 59 \%, 59 \%, 55 \%, 48 \%$, or $38 \%$. Given these coverage levels, the deductible ranges from $50 \%$ to $15 \%$. To mitigate moral hazard, deep-loss agricultural insurance polices such as RP incentivize the farmer to choose a larger deductible by offering higher ad valorem premium subsidies for lower coverage levels. Expected RP indemnity payments to the farmer are

$$
\iint R P p d G_{\varepsilon^{C}}\left(\tilde{\epsilon}^{p}, \tilde{\varepsilon}\right)=\sigma^{R P}(\eta) \theta^{R P} .
$$

Both RP and YP are coupled policies because farmers can affect both the size and frequency of payments by influencing yield through input choices, resulting in moral hazard. As in all insurance markets where moral hazard occurs, crop insurance companies shift some risk to farmers by instituting a deductible by offering only incomplete coverage ( $\eta$ is less than $100 \%$ ).

11 We model optional units instead of enterprise units because, based on survey data reported in Luitel et al. (2015a), only $28 \%$ of cotton farmers in Texas elected enterprise units. 


\subsection{Shallow-Loss Crop Insurance Policies}

The 2014 Farm Bill offers two new policies (STAX and SCO) to cotton farmers to potentially ${ }^{12}$ cover part of the deductible of the deep-loss policies. Payments under these two policies do not depend on farm-level random yield. Therefore, STAX and SCO are decoupled from a farmer's production decisions. Although farmers cannot affect the size or frequencies of payments by influencing yield (the coupling effect), these policies can still influence input uses through the well-known wealth and insurance effects (see Luckstead and Devadoss, 2016; Moschini and Hennessy, 2001).

Farmers can enroll only in STAX or in combination with a deep-loss insurance policy. STAX indemnity payments $(S T A X i)$ are

$$
\begin{aligned}
S T A X i= & \min \left[\max \left\{\zeta-\frac{\tilde{p} \tilde{y}^{C}}{\max \left[\tilde{p}, p^{F}\right] \max \left[y^{C}, y^{C O}\right]}, 0\right\},\right. \\
& (\zeta-\max [\eta, 0.70])] \times \\
& \phi \max \left[\tilde{p}, p^{F}\right] \max \left[y^{C}, y^{C O}\right],
\end{aligned}
$$

where $\zeta$ is the STAX coverage level which ranges from $\max [\eta, 0.70]$ to 0.90 in increments of $0.05 ; \tilde{y}^{C}=y^{C}+\tilde{\epsilon}^{C}$ is the random county yield equal to the average county yield $y^{C}$ plus the county random term $\tilde{\epsilon}^{C}$ centered on zero; $y^{C O}$ is the 5-year olympic average county yield; and $\phi \in[0.8,1.2]$ is the protection factor. A payment is triggered when actual county revenue $\left(\tilde{p} \tilde{y}^{C}\right)$ falls below the benchmark county revenue $\left(\max \left[\tilde{p}, p^{F}\right] \max \left[y^{C}, y^{C O}\right]\right)$ by more than the STAX coverage level $\zeta$. However, the actual payment rate is the minimum of this shortfall or $(\zeta-\max [\eta, 0.70])$. Consequently, the lower bound of the payment rate depends on $\max [\eta, 0.70]$. STAX indemnity payments equal the payment rate times the protection factor times the benchmark county revenue. To enroll in the STAX program, farmers pay the actuarially fair premium $\theta^{S T A X}=$ $\iint S T A X i d G_{\epsilon}\left(\tilde{\epsilon}^{p}, \tilde{\epsilon}^{C}\right)$, where $G_{\epsilon}\left(\tilde{\epsilon}^{p}, \tilde{\epsilon}^{C}\right)$ is the marginal cumulative density. The government subsidizes the premium at a fixed rate of $\sigma^{S T A X}=0.8$. Net STAX indemnity payments $(S T A X p)$ are

$$
S T A X p=S T A X i-\left(1-\sigma^{S T A X}\right) \theta^{S T A X} .
$$

Expected STAX indemnity payments are

$$
\iint \operatorname{STAX} p d G_{\epsilon}\left(\tilde{\epsilon}^{p}, \tilde{\epsilon}^{C}\right)=\sigma^{S T A X} \theta^{S T A X} .
$$

SCO is a shallow loss program in that it potentially covers part of the deductible portion of RP or YP policies. Furthermore, if the farmer selects RP,

12 Again, because of basis risk, there is no guarantee that STAX or SCO will actually cover the RP or YP deductible. 
then SCO provides revenue protection on the RP deductible. On the other hand, if the farmer selects YP, then SCO provides yield protection on the YP deductible. Also, in contrast to STAX participation, the farmer must be enrolled in a deeploss insurance policy to be eligible for the SCO policy. SCO indemnity payments $(\mathrm{SCO} i)$ are

$$
S C O i=\min \left[\max \left\{0.86-\frac{\tilde{p} \tilde{y}^{C}}{\max \left[\tilde{p}, p^{F}\right] y^{\mathrm{C}}}, 0\right\},(0.86-\eta)\right] \max \left[\tilde{p}, p^{F}\right] y^{A} \text {. }
$$

Farmers receive an indemnity payment if actual county revenue $\left(\tilde{p} \tilde{y}^{C}\right)$ falls below the county-revenue guarantee $\left(\max \left[\tilde{p}, p^{F}\right] y^{C}\right)$ by more than the coverage rate of $86 \%$. The actual payment rate depends on the minimum of this shortfall or $(0.86-\eta)$, implying the lower bound of this rate depends on the deep-loss coverage rate $\eta$. The SCO indemnity payment is equal to the payment rate times the liability $\left(\max \left[\tilde{p}, p^{F}\right] y^{A}\right)$. As an example, if the farmer selects RP for their deep loss insurance with a coverage rate of $\eta=70 \%$, then the farmer is left with a $30 \%$ deductible. As specified in the 2014 Farm Bill, SCO can potentially cover part of this deductible, leaving the farmer to incur a $14 \%$ deductible. In this example, if county revenue falls anywhere between $14 \%$ to $30 \%$ below the county-revenue guarantee, an SCO payment is triggered. However, if county revenue falls below $30 \%$ of the county-revenue guarantee, SCO payments are capped, but RP payments will be triggered if farm-level revenues fall below their revenue guarantee.

To enroll in the SCO program, farmers pay the actuarially fair premium $\theta^{S C O}=\iint S C O i d G_{\epsilon}\left(\tilde{\epsilon}^{p}, \tilde{\epsilon}^{C}\right)$. The government subsidizes the SCO premium at a fixed rate of $\sigma^{S C O}=0.65$. Then, net SCO indemnity payments $(S C O p)$ are

$$
S C O p=S C O i-\left(1-\sigma^{S C O}\right) \theta^{S C O} \text {. }
$$

Expected SCO indemnity payments are

$$
\iint[S C O p] d G_{\epsilon}\left(\tilde{\epsilon}^{p}, \tilde{\epsilon}^{C}\right)=\sigma^{S C O} \theta^{S C O} .
$$

As shown by equations (8) and (11), SCO indemnity payments are similar in structure to STAX indemnity payments, but SCO is less flexible as the coverage rate is fixed at $86 \%$ (leaving farmers with a $14 \%$ deductible) and does not have the protection factor. Furthermore, the SCO liability is based on farmer's APH yield as opposed to county yields.

\subsection{Optimization Problem}

A risk-averse farmer maximizes the expected value of utility from farm profits by optimally choosing inputs $x$, individual crop insurance coverage rate $\eta$, STAX 
coverage rate $\zeta$, and the protection factor $\phi$ :

$$
\max _{x, \eta, \zeta, \phi} \iiint U[\pi(\tilde{y}, \tilde{p})] d G\left(\tilde{\epsilon}^{p}, \tilde{\epsilon}, \tilde{\epsilon}^{C}\right),
$$

where profits come from one of the four following options: (a) market revenues ${ }^{13}$ minus total cost: $\pi=\tilde{r}-t c$; (b) market revenues minus total cost plus payments from deep loss (RP or YP) insurance: $\pi=\tilde{r}-t c+(R P p$ or $Y P p)$; (c) market revenues minus total cost plus payments from deep loss $(R P$ or $Y P)$ insurance and shallow loss: $S T A X \pi=\tilde{r}-t c+(R P p$ or $Y P p+S T A X p)$; or (d) market revenues minus total cost plus payments from deep loss $(R P$ or $Y P)$ insurance and shallow loss: $S C O \pi=\tilde{r}-t c+(R P p$ or $Y P p+S C O p)$.

We consider the Expo-Power utility function for the analysis because it is highly flexible in characterizing the farmer's risk attitude. The Expo-Power utility function (Saha, Shumway, and Talpaz, 1994) is

$$
U=1-\exp \left(-\rho \pi^{\psi}\right),
$$

where $\rho<0(>0)$ is decreasing (increasing) relative risk aversion coefficient, and $\psi=1$ is constant, $\psi<1$ is decreasing, and $\psi>1$ is increasing absolute risk aversion coefficient. To compare the impact of policies on the farmer, we calculate the certainty equivalent

$$
C E=U^{-1}(E U)=\left[-\frac{1}{\rho} \log (1-E U)\right]^{\frac{1}{\psi}},
$$

where $E U$ is the expected utility given by equation (14). The certainty equivalent translates the expected utility into the dollar amount that a farmer would be willing to pay to eliminate all risk. A higher certainty equivalent corresponds to a higher expected utility level, implying that the farmer is better off.

\section{Data, Sources, and Model Parameterization}

We analyze a representative cotton farm from Texas because, according to the U.S. Department of Agriculture, National Agricultural Statistics Service (USDANASS, 2017), Texas is consistently the largest upland cotton producing state, accounting for $56.8 \%$ of production on 4.5 million acres in 2015 and $55.57 \%$ of production on 5.2 million acres in 2016. Within Texas, we focus on the Southern High Plains ${ }^{14}$ because this region is the largest agricultural district in Texas, accounting for about $50 \%$ of all cotton acres harvested in Texas.

To simulate the model, we need to characterize the $\operatorname{CDF} G\left(\tilde{\epsilon}^{p}, \tilde{\epsilon}, \tilde{\epsilon}^{C}\right)$, parameterize the production technology $\tilde{y}=\alpha+\beta x^{\gamma}+\tilde{\epsilon}$ and utility function

13 Our analysis focuses on revenue from cotton lint because the revenue from cottonseed covers the cost of ginning.

14 The larger cotton producing counties in the Southern High Plains include Dawson, Hockley, Lynn, Lubbock, and Crosby. 
Table 1. Summary Statistics for Lubbock County Real Price and Detrended Yield

\begin{tabular}{lrrrr}
\hline \hline & Minimum & Mean & Maximum & Standard Deviation \\
\hline Price & 0.45 & 0.66 & 0.89 & 0.09 \\
County yield & 128.80 & 400.56 & 854.50 & 150.56 \\
\hline \hline
\end{tabular}

$U=1-\exp \left(-\rho \pi^{\psi}\right)$, and specify policy parameters. To estimate the CDF, we collect yield and price data for Lubbock County in the Southern High Plains from USDA-NASS (2017) for the years 1972 to 2015. Because county-level yield is an average of all the farms' yields in that county, an individual farm is riskier than the county. Consequently, following Goodwin (2009), we generate farmlevel yield data by adding additional noise-by randomly drawing from $N(0, \sigma)$, where $\sigma$ is $75 \%$ of the county-level standard deviation-to the county-level yield data.

The upland cotton price is detrended by deflating it with the Producer Price Index for raw cotton collected from U.S. Department of Labor, Bureau of Labor Statistics (2016). To center the detrended price data on zero, we subtract the mean price from each observation. The county-level yield data are detrended using LOESS regression ${ }^{15}$ to account for changes in the rate of technological progress over time. Then the yield data are normalized by subtracting the mean yield to center it on zero. Summary statistics for real price and detrended country yield are provided in Table 1 . We apply nonparametric kernel density estimation, which is free of any assumption on the functional form of the distribution, to characterize the trivariate CDF. ${ }^{16}$ Figure 1 graphs the marginal distributions of price and county-level yield. The marginal distribution for the price suggests it is skewed right, with a skewness of 0.79 . The yield distribution is also asymmetrical, which is more pronounced than the price distribution, as confirmed by the larger skewness of 0.88 . Because the marginal distribution of farm-level yield resembles the marginal distribution of county-level yield, but with a wider dispersion, it is not presented.

To parameterize the production technology, we use 0.6 for the returns to scale parameter $\gamma$. Baseline profits are zero, which is consistent with long-run equilibrium value of a competition firm. The price for the composite variable input is normalized to 1 , resulting in the value of variable cost equal to the

15 We employ the generalized cross-validation method, which suggests a smoothing parameter of 0.75 to minimize overfitting. Furthermore, the $P$ value for the Breusch-Pagan test for heteroskedasticity is 0.23 , implying no heteroskedasticity in the error term. In the online supplementary appendix (Figure A1), we analyze the sensitivity of the results to the detrending method by rerunning the analysis employing Spline regression with a smoothing parameter of 1.499 and quadratic detrending methods.

16 We use generalized product kernels with adaptive bandwidths. We also conducted the analysis based on the multivariate kernels with adaptive bandwidths, which generates fairly similar results as generalized product kernels. 

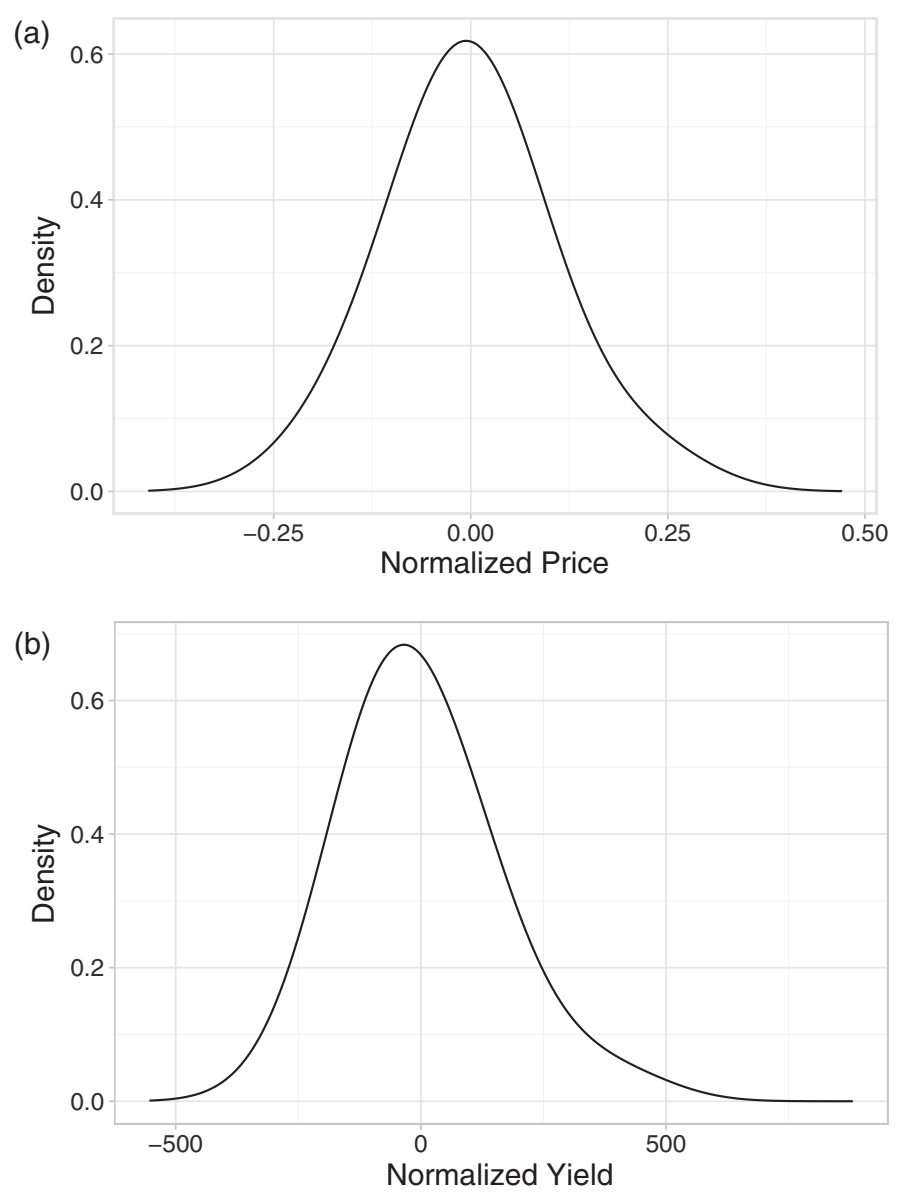

Figure 1. Marginal Distributions of Price (a) and County-Level Yield (b)

quantity. The expected market price is $\$ 0.66$ per pound, and expected yield is 383.91 pounds per acre. Based on historical detrended yield data in Lubbock County, we assume the yield $\alpha$ under the planting date requirement is 280 pounds per acre. For the utility function, we consider $\rho=0.1$ for a moderate level of risk aversion ${ }^{17}$ and use $\psi=0.3654$ for decreasing absolute risk aversion, which was obtained from Saha, Shumway, and Talpaz (1994).

Next, we turn to calibration of the productivity parameter $\beta$ and fixed production costs $f$. Because we consider a risk-averse cotton farmer, as implied by the concave utility function, and production decisions are being made via the expected utility function given by equation (14), standard calibration methods for the production technology cannot be employed here. The model is calibrated

17 We also considered a range of values for $\rho$ from 0.001 to 0.2 , and the results are fairly stable for these values, which ensures the concavity of the utility function. 
with no policies in place, implying $\pi=\tilde{r}-t c$. Given the previously discussed distribution characterization and parameters, we calibrate $\beta$ and $f$ to match two facts: the farmer's yield matches the average yield in Lubbock County and zero long-run profits for an average year $\left(\tilde{\epsilon}=0\right.$ and $\tilde{\epsilon}^{p}=0$ per pound). Because data sources do not report post-planting date requirement input use $x$ and to ensure $\beta$ and $f$ lead to the optimal input use in the baseline, the calibration routine must also simultaneously solve for inputs $x$. Therefore, the calibration routine solves for three unknowns $(\beta, f$, and $x)$ using the system of three independent equations: ${ }^{18}$

$$
\begin{aligned}
& \frac{\partial}{\partial x} \iiint U[\pi(x ; \tilde{\epsilon}, \tilde{p})] d G\left(\tilde{p}, \tilde{\epsilon}, \tilde{\epsilon}^{C}\right)=0 \\
& \alpha+\beta x^{\gamma}=y^{C} \\
& p\left(\alpha+\beta x^{\gamma}\right)-w x-f=0 .
\end{aligned}
$$

Solving this system of equations yields $\beta=12.05, f=216.80$, and $x=46.46$.

The APH yield is 366.43 , which is calculated as the 6-year average farmlevel yield. ${ }^{19}$ The 5 -year olympic average yield for Lubbock County is $y^{C O}=345$ lb./acre, which is computed from the county yield data.

To analyze how the additional farm-level variation in yield $\sigma$, risk-aversion coefficient $\rho$, yield $\alpha$ under the planting date requirement, and returns to scale $\gamma$ assumptions affect the results, we conduct sensitivity analysis by decreasing and increasing these parameters by $10 \%$.

\section{Results}

The simulation analysis is performed by numerically optimizing expected utility (equation 14). In doing so, this article advances the literature by optimally determining input use, the YP and RP coverage levels, the STAX coverage level, and STAX protection factor. The baseline simulation does not include any policies, and farm revenues come only from market sales. Thus, the baseline replicates the benchmark yield data discussed in the previous section. We consider four alternate scenarios where net farm revenues come from market sales plus insurance from (a) YP, (b) RP, (c) RP and STAX, or (d) RP and SCO. The alternate scenarios are compared with the baseline to analyze the impacts of different insurance policy options. Table 2 presents the results of the baseline and these four scenarios for yield, certainty equivalents, premiums, and expected payments. ${ }^{20}$

18 For optimal input use given in the first equation, we employ a numeric derivative.

19 According to the 2014 Farm Bill, the APH yield is calculated as the historic average yield with a minimum of 4 and a maximum of 10 years of records (Edwards, 2017).

20 See equations (4), (7), (10), and (13), respectively, for expected payment calculations for YP, RP, STAX, and SCO. 
Table 2. Simulation Results

\begin{tabular}{|c|c|c|c|c|c|}
\hline & Baseline Value & YP & $\mathrm{RP}$ & RP and STAX & $\mathrm{RP}$ and $\mathrm{SCO}$ \\
\hline & & & & $\%$ Change & \\
\hline Yield & $383.91 \mathrm{bu} /$ acre & -9.14 & -10.52 & -9.85 & -5.79 \\
\hline Certainty equivalent & $\$ 69.59$ & 44.15 & 49.84 & 79.97 & 67.7 \\
\hline \multirow[t]{2}{*}{ Coverage level } & & 80 & 80 & $\begin{array}{l}\% \\
70 \text { and } 90\end{array}$ & 50 and 86 \\
\hline & & & & \$/acre & \\
\hline YP premium & & 32.33 & & & \\
\hline YP net indemnity payment & & 15.52 & & & \\
\hline $\mathrm{RP}$ premium & & & 39.31 & 28.77 & 13.78 \\
\hline RP net indemnity payment & & & 18.87 & 16.97 & 9.24 \\
\hline STAX premium & & & & 23.73 & \\
\hline STAX net indemnity payment & & & & 18.98 & \\
\hline SCO premium & & & & & 24.94 \\
\hline SCO net indemnity payment & & & & & 16.21 \\
\hline
\end{tabular}

Notes: RP, Revenue Protection; SCO, Supplemental Coverage Option; STAX, Stacked Income Protection Plan; YP, Yield Protection.

If the representative cotton farmer described in the data section considers only the YP policy, the optimal coverage level is $80 \%$, with a corresponding premium subsidy rate of $48 \%$. Under the YP policy, the farmer has an incentive to influence the input use and yield, leading to moral hazard, ${ }^{21}$ to augment insurance payments. Consequently, the yield declines under the YP policy by $9.14 \%$. The certainty equivalent increases by $44.15 \%$, and the net YP indemnity payment is $\$ 15.52$ per acre (see equation 4$)$.

Next, we examine the RP policy. The optimal RP coverage level is also $80 \%$, with a corresponding premium subsidy rate of $48 \%$. Earlier studies also found similar RP insurance coverage levels: $80 \%$ by Bulut and Collins (2014) and 85\% by Davis, Anderson, and Smith (2014). The farmer adjusts inputs and thus yield (moral hazard) to maximize utility from income received from both the market and RP insurance payments. To increase the probability of receiving larger indemnity payments, the farmer reduces yield by $10.52 \%$ from the baseline. Thus, the input effect is larger in RP than in YP, as yield declines more under the former policy than under the latter. At the $80 \%$ coverage level, the farmer is charged an actuarially fair premium of $\$ 39.31$ per acre, and with the $48 \%$ premium subsidy rate, the farmer receives net RP indemnity payments of $\$ 18.87$ per acre (see equation 7). Because the RP policy reduces risk, the risk-averse

21 Although a reduction in input use is a result of moral hazard, the use of a composite input does not allow for the risk reducing and risk enhancing effect of different inputs, which can lead to bias in the moral hazard effect. 
farmer prefers the RP insurance policy to the baseline with no insurance as evidenced by the $49.84 \%$ increase in their certainty equivalent.

Because YP insures against only yield variability, it generates a lower increase in the certainty equivalent $(44.15 \%)$ compared with that of RP $(49.84 \%)$, which is largely driven by the relative low YP expected indemnity payment of $\$ 15.52$ per acre. Therefore, the representative farmer would select RP over YP. This result is consistent with USDA, Risk Management Agency (USDA-RMA) data that show on average the majority of farmers enroll in revenue protection $(83.48 \%)$ compared with yield protection $(0.06 \%)$ for the period $2015-2017$ (USDA-RMA, 2015). Because YP is not popular among cotton farmers, the remainder of this section focuses on RP in conjunction with STAX and SCO.

Even though farmers can choose STAX as a stand-alone policy, the enrollment data show that farmers most frequently opt for the RP and STAX combination. Therefore, we implement RP and STAX together in our analysis. The results show that the farmer chooses the maximum allowable multiplier factor of 1.2, which corroborates the findings of Davis, Anderson, and Smith (2014). For the RP and STAX policy combination, the farmer optimally chooses the upper bound for the STAX coverage level of $90 \%$ and the RP optimal coverage level of $70 \%$ (with a corresponding premium subsidy rate of $59 \%$ ), which results in the highest chance for STAX to cover part of the RP deductible. Because STAX is a county-based policy and RP is a farm-based policy, basis risk between the two policies exists and the farmer cannot necessarily count on STAX to fully cover the RP deductible in all possible outcomes. These results are similar to those of Luitel et al. (2015b) and comparable to the findings by Bulut and Collins (2014), who concluded the optimal coverage level for RP is $75 \%$ and for STAX is $90 \%$.

Despite leaving the farmer with only a $10 \%$ deductible, this policy combination affects optimal input as yield declines by $9.85 \%$. Therefore, from a moral hazard stance, the RP and STAX combination has a smaller impact than the RP policy alone. From the farmer's perspective, RP and STAX are preferred to $\mathrm{RP}$ alone because of a large increase in the certainty equivalent $(79.97 \%)$ under RP and STAX than under only RP. Under the RP and STAX combination, relative to RP only, the RP premium declines by $\$ 10.54$ per acre to $\$ 28.77$ per acre, and the expected net indemnity payment falls by $\$ 1.90$ per acre to $\$ 16.97$ per acre. The farmer now also pays a STAX premium of $\$ 23.73$ per acre and can expect net STAX indemnity payments of $\$ 18.98$ per acre (see equation 10$)$. Therefore, the farmer can expect combined indemnity payments of $\$ 35.95$ per acre.

The final scenario includes the policy combination of RP and SCO. Because the SCO coverage rate is fixed at $86 \%$ and the lower bound of the SCO payment rate depends on the RP coverage level, the lowest coverage level of $50 \%$ (which also provides the farmer with the highest premium subsidy of $67 \%$ ) is now optimal for RP insurance. This RP coverage level implies the farmer has the highest RP deductible; however, with the SCO coverage rate of $86 \%$, the farmer is only 
responsible for a $14 \%$ deductible. Note that, similar to STAX, the SCO payment rate is also based on county-level shortfalls.

The RP and SCO policy combination, with a $14 \%$ deductible, has the smallest effect on optimal input use of all policy options considered, as yield declines by only $5.79 \%$. The rationale for this result is that with the $50 \%$ deductible for RP, the farmer is less reliant on this coupled policy, which provides less incentive for the farmer to influence the production decision to alter the yield, and thus the RP and SCO combination has the smallest impact on input use (i.e., the moral hazard effect is the smallest).

Relative to the RP policy alone, adding SCO coverage reduces the RP premium by $\$ 25.53$ per acre to $\$ 13.78$ per acre. Therefore, given the $67 \%$ RP premium subsidy, the farmer can expect net RP indemnity payments of $\$ 9.24$ per acre. The SCO premium is $\$ 24.94$ per acre, and with the SCO premium subsidy of $65 \%$, the farmer can expect net SCO indemnity payments of $\$ 16.21$ per acre (see equation 13). Consequently, the combined net indemnity payment for both RP and SCO is $\$ 25.45$ per acre. With an increase in the certainty equivalent of $67.70 \%$, the farmer prefers RP and SCO over RP but not over RP and STAX.

Based on the USDA-RMA (2017) Summary of Business, an average of 1,792.33 insurance policies were sold over 2015-2017 in Lubbock County, Texas. Of these polices sold, RP, YP, SCO, STAX, and RP-HPE (revenue protection with harvest price exclusion) accounted for $83.48 \%, 0.06 \%, 9.96 \%$, $6.38 \%$, and $0.01 \%$, respectively. Thus, RP is clearly the most popular insurance followed by SCO and STAX. Focusing on RP, $25.60 \%, 28.42 \%$, and $36.90 \%$ of farmers enrolled at the $60 \%, 65 \%$, and $70 \%$ coverage levels, whereas only $2.92 \%, 0.33 \%$, and $0.02 \%$ of farmers enrolled at the $75 \%, 80 \%$, and $85 \%$ coverage levels. Thus, based on the previous analysis, farmers are underinsuring, particularly when enrolling in RP alone.

From these results, we can conclude that inclusion of the shallow-loss programs STAX and SCO lowers the optimal coverage rates for RP, which supports the findings of Davis, Anderson, and Smith (2014) and Bulut and Collins (2014). Furthermore, RP and STAX is the optimal policy for a cotton farmer, which corroborates the findings of Campiche (2013a) and Davis, Anderson, and Smith (2014).

\section{Sensitivity Analysis}

In this section, we conduct sensitivity analysis for additional farm-level variation in yield $\sigma$, risk-aversion coefficient $\rho$, yield $\alpha$ under the planting date requirement, returns to scale $\gamma$, and farm-level efficiency $\beta$ to determine how the results are affected by a $10 \%$ decrease and increase in these parameters. This analysis provides important insight into how heterogeneous farms within a county respond to the policies. Here, we focus on yield changes and total expected 
Table 3. Sensitivity Analysis Results

\begin{tabular}{|c|c|c|}
\hline & \multicolumn{2}{|c|}{ RP and STAX } \\
\hline & $10 \%$ Decrease & $10 \%$ Increase \\
\hline & \multicolumn{2}{|c|}{ Yield Variation $(\sigma)$} \\
\hline Yield ( $\%$ change) & -9.36 & -10.01 \\
\hline \multirow[t]{2}{*}{ Total net indemnity payment (\$/acre) } & 34.93 & 39.51 \\
\hline & \multicolumn{2}{|c|}{ Risk-Aversion Coefficient $(\rho)$} \\
\hline Yield ( $\%$ change) & -9.36 & -9.91 \\
\hline \multirow[t]{2}{*}{ Total net indemnity payment (\$/acre) } & 35.71 & 35.94 \\
\hline & \multicolumn{2}{|c|}{ Planting Date Yield $(\alpha)$} \\
\hline Yield ( $\%$ change) & -12.50 & -6.73 \\
\hline \multirow[t]{2}{*}{ Total net indemnity payment (\$/acre) } & 39.94 & 35.44 \\
\hline & \multicolumn{2}{|c|}{ Returns to Scale $(\gamma)$} \\
\hline Yield ( $\%$ change) & -7.57 & -12.22 \\
\hline \multirow[t]{2}{*}{ Total net indemnity payment (\$/acre) } & 34.87 & 38.28 \\
\hline & \multicolumn{2}{|c|}{ Farm Efficiency $(\beta)$} \\
\hline Yield ( $\%$ change) & -11.51 & -5.00 \\
\hline Total net indemnity payment (\$/acre) & 36.49 & 32.14 \\
\hline
\end{tabular}

indemnity payments under RP and STAX because this policy combination is the optimal option for the farmer (see Table 3). However, the results of the sensitivity analyses for other policies and variables are available from the authors upon request. For all sensitivity analyses, the conclusion that RP and SCO have the lowest moral hazard effect and the farmer benefits most from RP and STAX continues to hold, indicating robustness of the model and main findings to different values of these parameters.

For a $10 \%$ decrease and increase in farm-level yield variation $\sigma$ and riskaversion coefficient $\rho$, yield changes and expected payments are relatively stable, indicating the results are robust to the changes in these parameters. For changes in the yield $\alpha$ under the planting date requirement, optimal yield responds modestly compared with $-9.85 \%$ in Table 2 . When $\alpha$ is lowered by $10 \%$, the farmer has additional flexibility to influence yield to avail higher indemnity payments. In contrast, when $\alpha$ is increased by $10 \%$, the farmer has less flexibility to enhance indemnity payments. However, the influence of $\alpha$ on the total expected payments is relatively small. The returns to scale parameter $\gamma$ also exerts impact on yield. For a smaller $\gamma$, the effect of variable input on yield is less, whereas for a larger $\gamma$, the effect of variable input on yield is greater. The response of total expected payments to changes in $\gamma$ is fairly stable. A $10 \%$ higher and lower farm efficiency result in a baseline yield of 373.52 and 394.30 bu./acre, respectively. For more (less) efficient farms, a larger (smaller) portion of their revenues comes from market sales, and thus they have smaller (greater) incentive to reduce yield to secure indemnity payments. These sensitivity results extend the analysis beyond the representative farm in the county by highlighting how heterogeneous farms 
differing in various farm characteristics within a country respond to the RP and STAX policy combination.

\section{Conclusions}

This study develops a model for a risk-averse cotton farmer to analyze the impact of deep-loss (revenue and yield protection) and shallow-loss (STAX and SCO) crop insurance policies legislated in the 2014 Farm Bill. The model is calibrated to a representative cotton farm and numerically optimized to quantify the effects of different crop insurance policy combinations on yield (i.e., moral hazard), optimal insurance coverage levels, premiums, and insurance payments. Furthermore, based on certainty equivalent analyses, the model determines the optimal combination of insurance polices for the representative cotton farmer.

The results show that the RP and SCO combination has the lowest reduction in yield. Because the farmer can affect the size of RP indemnity payments by adjusting yield through input application, RP is coupled to production, whereas, because the farmer cannot influence the size of the STAX or SCO payments, these policies are decoupled from production. Therefore, by shifting insurance payments from the coupled RP policy to the decoupled STAX or SCO policy, the farmer has less incentive to adjust inputs and production to augment payments, which diminishes the moral hazard effect. Furthermore, to purchase cotton insurance, farmers have to undertake planting by a stipulated date. This means that farmers have only limited options to adjust the technology after planting and before harvest and thus have minimal ability to influence yield. A potential policy implication is that moral hazard could be further reduced by decoupling RP and YP insurance policies (i.e., by basing these policies on county-level yield rather than farm-level yield, because an individual farmer cannot receive higher payments by influencing the farm-level yield).

When the farmer elects only RP, the optimal coverage rate is $80 \%$. However, when shallow-loss coverage is added to RP, the farmer increases the RP deductible to the largest level that the shallow-loss policy will likely cover. With the inclusion of STAX, the RP coverage rate is $70 \%$ (with a RP deductible of $30 \%$ ), and concurrently, the farmer minimizes the STAX deductible by choosing a STAX coverage rate of $90 \%$ (with the smallest STAX deductible of $10 \%$ ). With the inclusion of SCO, the optimal RP coverage rate is $50 \%$ (with an RP deductible of $50 \%$ ), and the government set SCO coverage rate is $86 \%$ (with a SCO deductible of $14 \%$ ). The results also show that RP and STAX is the optimal policy combination, as evident from the largest gain in the certainty equivalent.

We conduct several sensitivity analyses based on differing farm characteristics, which capture the heterogeneity among farms. In doing so, our study extends beyond the representative-farm analysis. 


\section{References}

Adhikari, S. "Optimal Coverage Level and Producer Participation in Supplemental Coverage Option in Yield and Revenue Protection Crop Insurance." Paper presented at the Agricultural and Applied Economics Association and Western Agricultural Economics Association Annual Meeting, San Francisco, California, July 26-28, 2015.

Barnett, B.J., and O. Mahul. "Weather Index Insurance for Agriculture and Rural Areas in Lower-Income Countries." American Journal of Agricultural Economics 89,5(2007):1241-47.

Bulut, H., and K. Collins. "Designing Farm Supplemental Revenue Coverage Options on Top of Crop Insurance Coverage.” Agricultural Finance Review 74,3(2014):397-426.

Campiche, J. "Analysis of the STAX and SCO Programs for Cotton Producers." Paper presented at the 2013 AAEA: Crop Insurance and the Farm Bill Symposium, Louisville, Kentucky, October 8-9, 2013a.

Campiche, J. "Details of the Proposed Stacked Income Protection Plan (STAX) Program for Cotton Producers and Potential Strategies for Extension Education.” Journal of Agricultural and Applied Economics 45,3(2013b):569-75.

Campiche, J. "Theme Overview: Deciphering Key Provisions of the Agricultural Act of 2014." Choices 29,2(2014):1-4.

Davis, T.D., J.D. Anderson, and N.B. Smith. "Evaluating the Impact of Proposed Farm Bill Programs with Crop Insurance for Southern Crops.” Paper presented at the Southern Agricultural Economics Association Annual Meeting, Dallas, Texas, February 1-4, 2014.

Edwards, W. Proven Yields and Insurance Units for Crop Insurance. Ames: Iowa State University, Extension and Outreach . Technical Report Ag Decision Maker, File A1-55, 2017.

Goodwin, B.K. "Payment Limitations and Acreage Decisions under Risk Aversion: A Simulation Approach.” American Journal of Agricultural Economics 91,1(2009):19-41.

Karov, V., E.J. Wailes, and K.B. Watkins. Assessment of STAX (Stacked Income Protection Plan) for Arkansas Representative Panel Farms. Fayetteville: University of Arkansas Division of Agriculture, Department of Agricultural Economics and Agribusiness, 2012.

Luckstead, J., and S. Devadoss. "Implication of 2014 Farm Policies for Wheat Production." Paper presented at Agricultural and Applied Economics Association 2016 Annual Meeting, Boston, Massachusetts, July 31-August 2, 2016.

Luitel, K.P., D. Hudson, and T.O. Knight. "Understanding Cotton Producer's Crop Insurance Choices under the 2014 Farm Bill." Paper presented at the 2015 Agricultural and Applied Economics Association and Western Agricultural Economics Association Joint Annual Meeting, San Francisco, California, July 26-28, 2015 a.

Luitel, K.P., T.O. Knight, and D. Hudson. "Evaluation of Crop Insurance Choices for Cotton Producers under the 2014 Farm Bill.” Paper presented at the Southern Agricultural Economics Association 2015 Annual Meeting, Atlanta, Georgia, January 31-February $3,2015 b$.

Moschini, G., and D.A. Hennessy. "Uncertainty, Risk Aversion, and Risk Management for Agricultural Producers." Handbook of Agricultural Economics. Vol. 1A, Agricultural Production. B.L. Gardner and G.C. Rausser, eds. Amsterdam: Elsevier, 2001, pp. 88153.

Outlaw, J.L., J.W. Richardson, G.M. Knapek, J.M. Raulston, and B.K. Herbst. "Economic Impacts of the Safety Net Provisions in the 2012 Senate and House Farm Bills on AFPC's 
Representative Crop Farms.” Agricultural and Food Policy Center Working Paper 122, College Station: Agricultural and Food Policy Center, Department of Agricultural Economics, Texas A\&M University, 2012.

Roumasset, J., M. Rosegrant, U. Chakravorty, and J. Anderson. "Fertilizer and Crop Yield Variability: A Review." Variability in Grain Yields: Implications for Agricultural Research and Policy in Developing Countries. J. Anderson and P. Hazell, eds. Baltimore, MD: Johns Hopkins University Press, 1989, pp. 223-33.

Saha, A., C.R. Shumway, and H. Talpaz. "Joint Estimation of Risk Preference Structure and Technology Using Expo-Power Utility.” American Journal of Agricultural Economics 76,2(1994):173-84.

Skees, J.R., J.R. Black, and B.J. Barnett. "Designing and Rating an Area Yield Crop Insurance Contract." American Journal of Agricultural Economics 79,2(1997):430-38.

U.S. Department of Agriculture, Farm Service Agency. Cotton Transition Assistance Program (CTAP). 2014 Farm Bill, Fact Sheet, August 2014. Internet site: https://www.fsa.usda. gov/Internet/FSA_File/cotton_trans_asst_prog.pdf (Accessed November 20, 2016).

U.S. Department of Agriculture, National Agricultural Statistics Service (USDA-NASS). “Quick Stats.” Internet site: https://quickstats.nass.usda.gov/ (Accessed 2017).

U.S. Department of Agriculture, Risk Management Agency (USDA-RMA). "Summary of Business.” Internet site: http://prodwebnlb.rma.usda.gov/apps/SummaryofBusiness/ (Accessed October 27, 2015).

- "Summary of Business." Internet site: http://prodwebnlb.rma.usda.gov/apps/ SummaryofBusiness/ (Accessed August 27, 2017).

U.S. Department of Labor, Bureau of Labor Statistics. "Databases, Tables \& Calculators by Subject." Internet site: https://data.bls.gov/timeseries/wpu0151\%26output_view= pct_12mths (Accessed February 10, 2016).

Vedenov, D.V., and B.J. Barnett. "Efficiency of Weather Derivatives as Primary Crop Insurance Instruments." Journal of Agricultural and Resource Economics 29,3(2004):387-403. 